\title{
The Astrocytic Contribution in ALS: Inflammation and Excitotoxicity
}

\author{
Kim Staats ${ }^{1,2}$ and Ludo Van Den Bosch ${ }^{1,2}$ \\ ${ }^{1}$ University of Leuven, \\ ${ }^{2}$ VIB Vesalius Research Center, \\ Belgium
}

\section{Introduction}

Amyotrophic Lateral Sclerosis (ALS) is a devastating progressive neurodegenerative disease, due to the loss of motor neurons and denervation of muscle fibres, resulting in increasing muscle weakness and paralysis. The disease has an incidence of 2.7 cases per 100,000 people in Europe (Longroscino et al., 2010). It is diagnosed from teen years onward, but is more prevalent in the later years of life. In lack of a medical cure, average life expectancy post diagnosis is between 2 and 5 years, though 10\% of all patients live longer than 10 years. Patients mainly succumb to the disease by respiratory insufficiency or may opt for euthanasia where legislature permits (Maessen et al., 2010). Although ALS is characterised by degeneration of central nervous system tissue, mental functions remain largely unaffected resulting in a locked-in state (Kotchoubey et al., 2003). At current, there is but one medicine to treat the disease, riluzole, slowing disease progression moderately (Miller et al., 2007).

\subsection{Basic genetics of ALS}

Mutations in the ubiquitously expressed $\mathrm{Cu} / \mathrm{Zn}$ superoxide dismutase 1 (SOD1) gene can cause ALS. SOD1 detoxifies cell damaging free radicals and its mutations account for $20 \%$ of the ALS patients suffering from the disease by familial origin (fALS) worldwide. The remaining $90 \%$ of ALS patients suffer from the disease by unknown sporadic causes (sALS), though a common mechanism is predicted as fALS and sALS patients display indistinguishable clinical phenotypes. Overexpression of mutant forms of human SOD1 causes the ALS phenotype of transgenic SOD1 mice, accounting for an invaluable contribution to ALS research (Gurney et al., 1994). Many hallmarks of the disease are shared between patients and this rodent model, including specific motor neuron loss, aggregate formation, astrogliosis, microgliosis and progressive paralysis. As the genetic ablation of SOD1 does not produce an ALS-like phenotype in mice (Reaume et al., 1996; Shefner et al., 1999) the pathogenic mechanism of mutant SOD1 is a toxic gain of function. This gain of function may be exerted by protein misfolding, aggregation, impaired proteasome functioning, impaired retrograde transport, excitotoxic cell death or other mechanisms (reviewed in Bruijn et al., 2004). Mutations in other genes also cause familial ALS, including mutations in vesicle-associated membrane proteinassociated protein B (VAPB), TAR DNA binding protein (TDP-43), fused in 
sarcoma/translocated in liposarcoma (FUS/TLS), optineurin and valsolin containing protein (VCP) (Johnson et al.; Maruyama et al.; Rutherford et al., 2008; Van Deerlin et al., 2008; Del Bo et al., 2009; Kwiatkowski et al., 2009; Vance et al., 2009). Unfortunately, the discovery of these mutant genes has not yet progressed into useful ALS model organisms, so most of the work described below was conducted with mutant SOD1based ALS models.

\subsection{Non-cell autonomous ALS}

Multiple cell types contribute to the pathology making ALS a non-cell autonomous disease (Boillee et al., 2006a). By addition or deletion of mutant SOD1 in specific cell types, it is known that mutant SOD1 influences the disease depending on the cell type, including astrocytes (Yamanaka et al., 2008; Wang et al., 2011a), microglia (Boillee et al., 2006b), Schwann cells (Lobsiger et al., 2009) and motor neurons (Jaarsma et al., 2008). Additionally, ablation of T-cells (Beers et al., 2008; Chiu et al., 2008), B-cells (Naor et al., 2009), CD4+ and CD8+ cells (Beers et al., 2008) decrease survival of ALS mice, demonstrating the role of immune cells in disease progression. Although ALS is a non-cell autonomous disease, mutant SOD1 expressed solely in motor neurons is sufficient to initiate the disease, albeit with a slower disease progression (Jaarsma et al., 2008). Motor neurons in the motor cortex, brainstem and spinal cord undergo cell death selectively in patients. A number of hypotheses attempt to explain this cell type selectivity, including the long axons of the motor neurons (Fischer and Glass, 2007), their poor intracellular calcium buffering capacity (Grosskreutz et al., 2010) and motor neuron specific cell death pathways (Raoul et al., 2002; Raoul et al., 2006; Genestine et al., 2011).

The contribution of mutant SOD1 expressing astrocytes in the non-cell autonomous character of ALS has been studied by excising mutant SOD1 from astrocytes which increases survival in two different mutant SOD1 mouse models (Yamanaka et al., 2008; Wang et al., 2011a). These results denote the toxic character of mutant SOD1 in astrocytes that accelerate disease progression significantly by mechanisms such as, but not exclusively, the below described mechanisms of neuroinflammation and excitotoxicity. This is schematically presented in figure 1 .

\subsection{Neuroinflammation observed in ALS}

Neuroinflammation occurs in a number of neurodegenative diseases, including ALS (reviewed in Papadimitriou et al., 2010 and Philips and Robberecht, 2011), and entails the reactive state of astrocytes (astrogliosis) and microglia (microgliosis) and the infiltration of lymphocytes. Initially perceived as a bystander effect, neuroinflammation is currently seen as beneficial at first, removing damaged cells and secreting supportive factors, and potentially detrimental thereafter by excessive release of cytokines (Beers et al., 2011a). Evidence of inflammation is detected in post mortem tissue (Schiffer et al., 1996; Anneser et al., 2004; Casula et al., 2011; Sta et al., 2011; Wang et al., 2011b), in cerebrospinal fluid (CSF) (Baron et al., 2005; Tateishi et al., 2010) and in blood samples of ALS patients (Poloni et al., 2000). In accordance, similar parameters of neuroinflammation are detected in ALS rodent models (among many others in Kiaei et al., 2006; Keller et al., 2009; Beers et al., 2011b). Inflammation is generally perceived as hazardous in ALS, as increasing inflammation in ALS models exacerbates disease progression and diminishes survival (Nguyen et al., 2004; Gowing et al., 2009). Fittingly, therapeutic strategies targeting inflammation are often advantageous in ALS rodent models (see below). 


\subsection{Excitotoxicity in ALS}

An additional detrimental mechanism in ALS is excitotoxicity; an overstimulation of neurons causing neurodegeneration. Glutamate binds to the N-methyl D-aspartate (NMDA) or a-amino-3-hydroxy-5-methyl-4-isoxazole proprionic acid (AMPA) receptors, allowing extracellular sodium and calcium to enter motor neurons. Increased levels of intracellular calcium consequently cause neuronal cell death. The importance of excitotoxicity in ALS is demonstrated by the beneficial effects obtained by treating patients with riluzole. Although the precise mechanism of this drug is not yet known, it blocks NMDA receptors, enhances re-uptake of glutamate from the synaptic cleft and inhibits glutamate release by blocking voltage-gated sodium channels (Siniscalhi et al., 1999), thus preventing motor neuron cell death. Riluzole treatment increases predicted lifespan with a significant $12 \%$ in ALS mice (Bensimon et al., 1994; Lacomblez et al., 1996) and increases the probability of one year survival in patients by $9 \%$ (Miller et al., 2007). Unfortunately, it does not halt disease progression.

An overview of the current knowledge of the astrocytic contribution in ALS will be addressed in this chapter separately for the mechanisms inflammation and excitotoxicity.

\section{Astrocytes in inflammation}

Despite that microglia are the main immune cells of the central nervous system (reviewed in Ransohoff, 2010), astrocytes can also become reactive and contribute to neuroinflammation and are the focus of this chapter, with microglial inflammatory effects residing beyond the scope of this chapter. During neuroinjury or neurodegeneration the production of cytokines induce astrogliosis in which astrocytes increase glial fibrillary acidic protein (GFAP) and vimentin expression as well as an array of other genes. This response increases neuronal survival and includes both supportive factors (e.g. growth factors and glutamate transporters) and cytokines to sustain/promote neuroinflammation. Interestingly, during neuroinflammation the number of astrocytes increases by the differentiation of chondroitin sulfate proteoglycan, NG2, positive cells to astrocytes and not by astrocytic proliferation (Gowing et al., 2008).

\subsection{Increasing inflammation in ALS}

To assess the effect of inflammation in ALS and thus to discover whether boosting the inherent inflammation would be beneficial, lipopolysaccharide (LPS) was daily administered to ALS mice (Nguyen et al., 2004). The effect of this treatment was a clear decrease in lifespan, implying that an increase of inflammation is detrimental in ALS (Nguyen et al., 2004). Another study, initially intended to decrease inflammation, administered macrophage colony stimulating factor (M-CSF) to ALS mice and observed an unexpected increase of microgliosis also leading to a decreased survival (Gowing et al., 2009). Although not directed specifically at astrocytes, this work has led to the understanding of the hazardous character of neuroinflammation in ALS.

\subsection{Astrogliosis in ALS}

Reactive astrocytes alter gene expression including an upregulation of the intermediate filaments GFAP and vimentin that allow for visualisation of astrogliosis by increased immunoreactivity of these filaments in patient and ALS model tissue. Post mortem spinal 
cord tissue from fALS and sALS patients display astrogliosis (Schiffer et al., 1996), implying that reactivity of astrocytes is not limited to the familial form of ALS. Interestingly, astrogliosis levels are similar between long surviving and short surviving ALS patients, although this is not the case for microglial activation and the amount of dendritic cells (Sta et al., 2011). An extra facet of astrogliosis in ALS is an increased immunoreactivity of tolllike receptor 4 in astrocytes of sALS patients (Casula et al., 2011). Astrogliosis in ALS mice is present at symptomatic stages preceeding microgliosis (Kiaei et al., 2006; Keller et al., 2009; Yang et al., 2011). Interestingly, GFAP is not necessary for astrogliosis as GFAP deficient astrocytes can still become reactive and do not affect survival of ALS mice (Yoshii et al., 2011).

\subsection{Mutant SOD1 affects astrocytic inflammatory behaviour}

The expression of mutant SOD1 in astrocytes alters their function in vivo and in vitro. To begin, deletion of mutant SOD1 in astrocytes in two distinct ALS models demonstrates the detrimental effect of mutant SOD1 in astrocytes mainly post onset, as deletion increased lifespan of ALS mice (Yamanaka et al., 2008; Wang et al., 2011a). Intriguingly, astrogliosis was unaltered, implying that the negative effect of mutant SOD1 in astrocytes is not due to altered levels of astrogliosis (Yamanaka et al., 2008), but potentially by astrocytes inducing microgliosis (Yamanaka et al., 2008; Wang et al., 2011a). An alternative approach arrives from the field of transplantation in which non-transgenic mesenchymal stem cells are transplanted into the spinal cord of ALS rats and differentiate into astrocytes, thus diluting the mutant SOD1 positive astrocytes in the spinal cord (Boucherie et al., 2009). This approach also shows unaltered astrogliosis, but also decreased microgliosis and cyclooxygenase 2 (COX2) expression, and extends murine ALS life span (Boucherie et al., 2009). The processes explaining this hazardous effect of mutant SOD1 in astrocytes has been investigated in vitro. To begin, an interesting approach of transducing human astrocytes with wild-type SOD1 or mutant SOD1 increases inflammation in mutant SOD1 cultures (Marchetto et al., 2008). In addition, the mutant SOD1 transduced astrocytes provide a less viable environment for human embryonic stem cell derived motor neurons (Marchetto et al., 2008). The latter was rescued by using a NADPH oxidase 2 (NOX2) inhibitor, apocynin (Marchetto et al., 2008). Other studies concur that mutant SOD1 primary astrocytes exhibit a higher gene expression of cytokines on baseline and when stimulated by interferon $\gamma$ (IFN $\gamma$ ) or tumor necrosis factor a (TNFa) (Hensley et al., 2006), implying once again that mutant SOD1 expression may affect the threshold of astrocytes to produce proinflammatory cytokines. Accordingly, the expression of interferon simulated genes is detected in astrocytes of presymptomatic ALS mice (Wang et al., 2011b) and genetic ablation and knockdown of the interferon alpha receptor type 1 (IFNAR1) increase ALS mouse survival by $5 \%$ and $10 \%$, respectively (Wang et al., 2011b). Intriguingly, Aebischer et al. stress the importance of interferon signalling in mutant SOD1 astrocytes by demonstrating that mutant SOD1 astrocytes trigger the selective death of motor neurons mediated by IFNY (Aebischer et al., 2011). This mechanism is dependent on the activation of the lymphotoxin- $\beta$ receptor by LIGHT (TNFSF14) and genetic ablation of LIGHT extends survival of ALS mice by $13 \%$, but does not postpone disease onset (Aebischer et al., 2011). Although this is a large increase in disease survival, clearly other mechanisms remain to play a role.

The above described altered functioning of mutant SOD1 expressing astrocytes is induced by an overexpression of multiple copies of mutant SOD1. It is unclear whether these effects 
also play a role in fALS patients with only 1 allele of mutant SOD1 or in fALS/sALS patients without disease causing SOD1 mutations. Remarkable work by Haidet-Phillips et al., (2011) shows that astrocytes collected post mortem from fALS and sALS are both able to induced motor neuron selective death which is not observed with astrocytes obtained from controls (Haidet-Phillips et al., 2011). Gene expression analysis of the the fALS and sALS astrocytes demonstrated increased expression chemokines, proinflammatory cytokines and components of the complement pathway (Haidet-Phillips et al., 2011). This study confirms that the astrocytic inflammatory effects found in vitro and in vivo in ALS mice may also contribute to disease pathology in humans.

\subsection{Genetic tools to minimise astrogliosis}

Attempts to minimise the inflammatory effect of astrocytes in ALS include genetic strategies targeting astrocytic knockdown of certain cytokines. Targeting of nuclear factor $\mathrm{\kappa B}(\mathrm{NF}-\mathrm{kB})$ activation specifically in astrocytes does not alter disease onset nor life span in ALS mice (Crosio et al., 2011). Which may be in part due to the mere decreased astrogliosis at presymtomatic stage (Crosio et al., 2011). Additionally, complete ablation of TNFa does not affect disease parameters (Gowing et al., 2006), also implying deletion of a single cytokine may not be sufficient to affect disease progression, as a general decrease in inflammation can be beneficial (see below). Instead of targeting cytokine production, ablating proliferating astrocytes was attempted in ALS, showing no effect on survival (Lepore et al., 2008a). This may be explained by the inability of astrocytes to proliferate in ALS (Gowing et al., 2008).

\subsection{Therapeutic strategies targeting inflammation in ALS}

A number of strategies have been utilized to diminish inflammation in ALS mice, though often not specifically targeting astrocytes. It is worthwhile to note that it is commonly unclear whether anti-inflammatory strategies truly exert an anti-inflammatory function due to the age-matched analysis of astrogliosis instead of disease stage-matched analysis with drugs that successfully extend lifespan. Among these therapeutic strategies are those intended to pharmacologically block the cyclooxygenase (COX) pathway by administration of celecoxib, a selective COX-2 inhibitor, and deletion of the prostaglandin E2 receptor. Both strategies diminish inflammation, postpone disease onset and prolong survival in ALS mice (Drachman et al., 2002; Liang et al., 2008). Similarly, celastrol administration also postponed disease onset extended lifespan, while decreasing TNFa, nitric oxide synthases (iNOS), cluster of differentiation 40 (CD40) immunoreactivity and astrogliosis when assessing age-matched spinal cord tissue (Kiaei et al., 2005). Similar effects are obtained when providing ALS mice with folic acid (Zhang et al., 2008) or bee venom (Yang et al., 2010). Thalidomide extends survival in ALS mice by destabilising cytokine mRNA including TNFa (Kiaei et al., 2006). Additionally, its analog lenalidomide also prolongs survival (Kiaei et al., 2006), even when administered after symptom onset (Neymotin et al., 2009). To conclude, minocycline has shown a dramatic increase in survival of ALS mice and postpones symptom onset (Kriz et al., 2002; Van Den Bosch et al., 2002; Zhu et al., 2002). Interestingly, this effect is moment of administration dependent, as administration of minocycline post disease onset increases the astrocytic and microglial response in ALS mice, decreasing survival (Keller et al., 2011). 


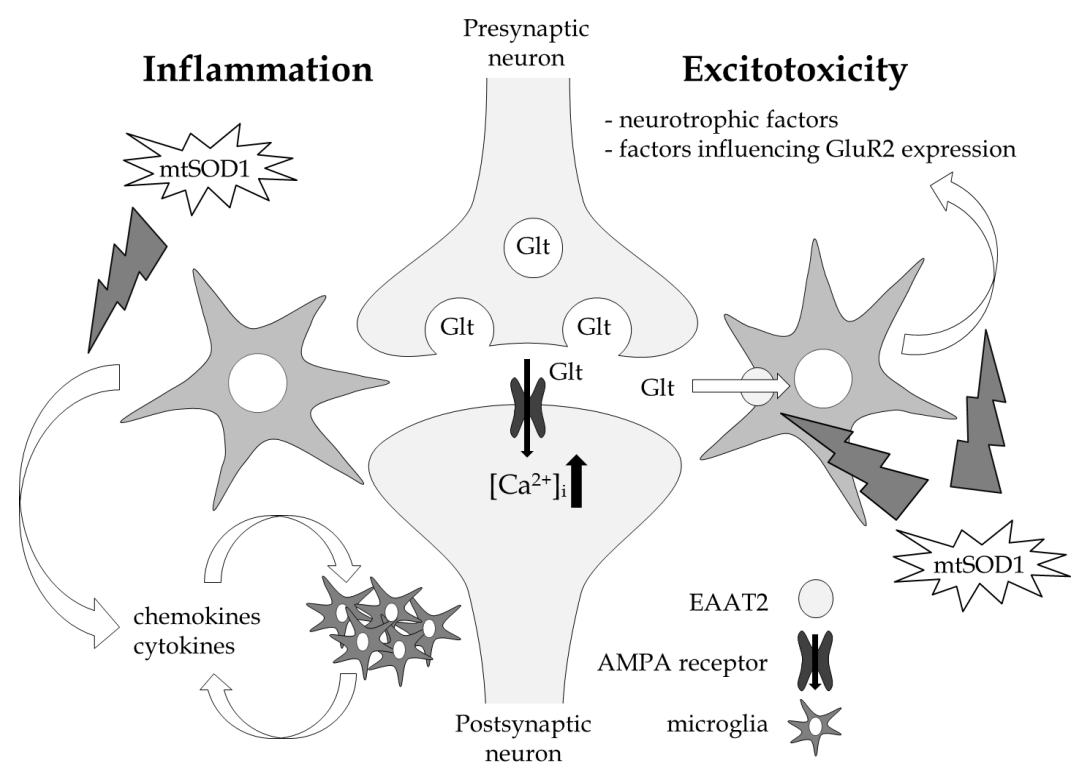

Fig. 1. Mutant SOD1 in astrocytes affecting (motor) neuron survival.

\section{Astrocytes in excitotoxicity}

In addition to the clear inflammatory role that astrocytes play in ALS, they also contribute to the mechanism of excitotoxicity. Their effect in the latter mechanism is two-fold: firstly, astrocytes facilitate the removal of excessive glutamate at the synaptic cleft and secondly, they affect the calcium permeability of AMPA receptors of motor neurons.

\subsection{Excitotoxicity in ALS explained}

Glutamate is the initiator of excitotoxicity in ALS. This neurotransmitter is the most abundant excitatory neurotransmitter in the brain and binds to NMDA, AMPA, and kainate (ionotropic) and metabotropic glutamate receptors (mGluR). Packaged into vesicles by the pre-synaptic neuron, glutamate is released into the synaptic cleft by the fusion of vesicles to the membrane of the neuron to excite the post synaptic neuron. This process is inhibited by riluzole (Siniscalhi et al., 1999). Increased levels of glutamate are detected in fALS, sALS (Fiszman et al., 2010; Spreux-Varoquaux et al., 2002) and is confirmed in spinal cords of ALS mice and rats. The detrimental role of glumate in the disease is demonstrated by the pronounced cell death that occurs to neurons in vitro when exposed to low levels of glutamate, even as low as physiologically detected in CSF (Cid et al., 2003). To further illustrate the detrimental role of glutamate in ALS, administration of compounds that block the formation of glutamate increase cell survival, both in vivo and in vitro (Cid et al., 2003).

\subsection{Astrocytes in excitotoxicity in ALS: EAAT2/GLT-1}

After glutamate release from the pre-synaptic neuron and binding of glutamate to ionotropic or metabotropic receptors on the post-synapse (increasing the concentration of 
intracellular calcium), glutamate is recycled for further use by the glial and endothelial cells, including astrocytes. Astrocytic glutamate re-uptake occurs by the glutamate transporters excitatory amino acid transporter 1 (EAAT1) and excitatory amino acid transporter 2 (EAAT2; also known as glutamate aspartate transporter (GLAST1) and glutamate transporter 1 (GLT-1), respectively). These transporters internalise glutamate, eg. into the astrocyte, for conversion to glutamine that is returned to the pre-synaptic neuron to be release again as glutamate (Laake et al., 1995).

Decreased glutamate uptake and EAAT2 protein levels are a common feature in both fALS and sALS and both in vitro and in vivo model systems (Staats and Van Den Bosch, 2009). In vitro transfection of primary cultured astrocytes with either mutant SOD1 or wild type human SOD1 down-regulates EAAT2 post transcriptionally (Tortarolo et al., 2004) and decreases EAAT2 transcription (Yang et al., 2009). Accordingly, glutamate transport is decreased in a neuronal cell line by mutant SOD1 transfection (Sala et al., 2005). Interestingly, this down-regulation also occurs in ALS model rats at pre-symptomatic stages through to end stage (Howland et al., 2002), at end stage only (Warita et al., 2002), in ALS model mice at end stage (Bendotti et al., 2001; Guo et al., 2010) and in post mortem patient spinal cords (Sasaki et al., 2001). In addition, in patient material the loss of EAAT2 and decreased tissue glutamate transport does not coincide with decreased levels of gene expression (Bristol and Rothstein, 1996), indicating that the loss is induced post transcriptionally, also in humans. Interestingly, a decrease of EAAT2 protein levels is not only in mutant SOD1 ALS models, but also a model of ALS/PDC (Wilson et al., 2003). In this model wild-type mice are fed with washed cycad flour containing $\beta$-methylaminoalanine (BMAA), which causes an ALS-like phenotype (Wilson et al., 2002). Although the loss of EAAT2 in ALS is apparent, it remains unclear whether this post transcriptional loss of EAAT2 proceeds or follows the loss of motor neurons.

\subsection{Targeting (astrocytic) EAAT2}

To assess whether the loss of glutamate transport or the loss of EAAT2 specifically results in motor neuron loss, pharmacological and genetic tools have been used. To begin, research conducted by pharmacologically inhibiting glutamate transport in the rat spinal cord, failed to show any motor neuron loss despite the increased levels of glutamate (Tovar et al., 2009). In contrast, a similar experiment has been performed to address whether EAAT2 loss specifically induces motor neuron loss. EAAT2 null mice live for approximately 6 weeks before they succumb to epileptic seizures and are vulnerability to acute brain injury (Tanaka et al., 1997). To this end, heterozygous mice demonstrated the effect of approximately $40 \%$ knockdown of EAAT2 in the spinal cord in ALS mice (Pardo et al., 2006). This knockdown resulted in a non-significant decrease of symptom onset and significant, but moderate, decrease of lifespan in ALS mice (Pardo et al., 2006).

To assess the expected beneficial role of EAAT2 in ALS, transgenic mice overexpressing human EAAT2 in specifically astrocytes were crossbred with mutant SOD1 mice. Although glutamate uptake is increased in vivo and an overexpression of human EAAT2 is protective on cortical neurons in vitro, an effect on symptom onset or lifespan was absent (Guo et al., 2003). Possibly, the expression levels were insufficient to induce an effect or human EAAT2 is not as efficient as murine EAAT2 in mouse, as administration of ceftriaxone (a $\beta$-lactam antibiotic) and GPI-1046 (a synthetic, non-immunosuppressive derivative of FK506) increase EAAT2 protein levels and extend lifespan of ALS mice (Rothstein et al., 2005; Ganel et al., 
2006) by enhancing EAAT2 transcription (Lee et al., 2008). In addition, EAAT2 is also expressed by other cells types than astrocytes alone (Anderson and Swanson, 2000), which are not targeted in this genetic experimental design. Interestingly, removal of mutant SOD1 from astrocytes leads to prolonged survival without affecting astrogliosis, but does preserve EAAT2 levels potentially explaining the extended lifespan (Wang et al., 2011a).

\subsection{Astrocytic replacement therapy in ALS mice}

The beneficial effect of EAAT2 is often used as an explanation of positive effects found by cell transfers in ALS model rodents. For instance, the systemic transplantation of c-kit positive cell from bone marrow in mutant SOD1 mice significantly increased the lifespan, which is, at least in part, attributed to increased EAAT2 expression induced by the transferred cells (Corti et al., 2010). The same holds true for the prolonged survival of ALS rats when treated with focal transplantation-based astrocyte replacement with wild type glial-restricted precursors (GRPs) (Lepore et al., 2008b). This study also focussed on EAAT2 by also transplanting EAAT2 overexpressing GRPs and EAAT2 null GRPs. The ALS mice treated with the EAAT2 overexpressing GRPs showed no additional increase of lifespan compared to wild type GRP treated ALS mice (already increased compared to controls). Intriguingly, this positive effect of transplantation of the wild type GRPs is diminished in mice transplanted with EAAT2 null GRPs (Lepore et al., 2008b). In addition, co-cultures of human adipose-derived stem cells with astrocytes induce higher levels of EAAT2 in astrocytes (Gu et al., 2010), though this treatment has not (yet) been shown to affect motor neuron survival in vitro or in vivo.

\subsection{Astrocytes in excitotoxicity in ALS: AMPA receptor permeability}

After the release of glutamate from the pre-synaptic neuron into the synaptic cleft, glutamate binds to NMDA, AMPA receptors or the metabotropic receptors. High levels of calcium entering through AMPA receptors into the post-synaptic neuron can cause neuronal death. The AMPA receptor is formed as a tetramer combining, usually pairwise, a combination of its four different subunits (glutamate receptor unit 1-4 (GluR1-4)) (Shi et al., 1999). Each subunit can bind glutamate and the channel opens after occupation of at least 2 binding locations (Mayer, 2005). The importance of this receptor in ALS is demonstrated by the ablation of glutamate induced apoptosis in cortical neurons in vitro (Cid et al., 2003) and in vivo when administering an AMPA receptor antagonist (Van Damme et al., 2003; Tortarolo et al., 2006).

The AMPA receptor plays an imperative role in excitotoxicity by its calcium permeability that is determined by the incorporation of the GluR2 subunit in the receptor complex. In most conditions, the AMPA receptor complex contains at least one GluR2 subunit and it prevents the influx of extracellular calcium into the neuron (Seeburg et al., 2001). In contrast, receptors lacking the GluR2 subunit are highly calcium permeable (Seeburg et al., 2001). A general decrease of GluR2 is found in ALS model mice, portraying an increased vulnerability of these mice to excitotoxic insults (Tortarolo et al., 2006; Zhao et al., 2008). The role of GluR2 in ALS is investigated by genetically ablating GluR2 in ALS mice, which decreases survival in vivo and decreases cell survival in vitro (Van Damme et al., 2005). The opposite has been shown by up-regulating GluR2 expression in motor neurons of ALS mice, as hereby survival is increased (Tateno et al., 2002). In addition, pharmacological inhibition of the AMPA receptor prolonged survival in ALS model mice (Van Damme et al., 2003; Tortarolo et al., 2006). 
Interestingly, the surrounding astrocytes influence the expression level of the GluR2 subunit in motor neurons, as soluble factor(s) released from astrocytes effect GluR2 gene expression and neuronal vulnerability to excitotoxic insults, both in vitro and in vivo (Van Damme et al., 2007). Moreover, the presence of mutant SOD1 interferes with the production and/or secretion of this factor(s) to increase GluR2 expression and thus decreases motor neuronal resistance to excitotoxicity (Van Damme et al., 2007).

\section{Conclusions and future directions}

Astrocytes clearly contribute to ALS decrease progression in both neuroinflammation and excitotoxicity. An intriguing aspect of astrocytes in ALS disease pathology is whether the mutant SOD1 astrocytic properties, of LIGHT dependent cell death and diminished GluR2 editing for example, are also important in other ALS causing mutations and in sporadic cases of ALS. Initial work performed implies that these characteristics are not solely dependent on mutant SOD1 in patients. In addition, both mechanisms in which astrocytes function seem successfully targetable in mice. Future research may benefit from further assessing the role of also non-SOD1 ALS causing mutations in astrocytes on ALS and optimizing therapeutic strategies against neuroinflammation and excitotoxicity.

\section{References}

Aebischer, J., Cassina, P., Otsmane, B., Moumen, A., Seilhean, D., Meininger, V., Barbeito, L., Pettmann, B., and Raoul, C. (2011). IFNgamma triggers a LIGHT-dependent selective death of motoneurons contributing to the non-cell-autonomous effects of mutant SOD1. Cell Death Differ 18, 754-768.

Anderson, C.M., and Swanson, R.A. (2000). Astrocyte glutamate transport: review of properties, regulation, and physiological functions. Glia 32, 1-14.

Anneser, J.M., Chahli, C., Ince, P.G., Borasio, G.D., and Shaw, P.J. (2004). Glial proliferation and metabotropic glutamate receptor expression in amyotrophic lateral sclerosis. $J$ Neuropathol Exp Neurol 63, 831-840.

Baron, P., Bussini, S., Cardin, V., Corbo, M., Conti, G., Galimberti, D., Scarpini, E., Bresolin, N., Wharton, S.B., Shaw, P.J., et al. (2005). Production of monocyte chemoattractant protein-1 in amyotrophic lateral sclerosis. Muscle Nerve 32, 541-544.

Beers, D.R., Henkel, J.S., Zhao, W., Wang, J., and Appel, S.H. (2008). CD4+ T cells support glial neuroprotection, slow disease progression, and modify glial morphology in an animal model of inherited ALS. Proc Natl Acad Sci U S A 105, 15558-15563.

Beers, D.R., Henkel, J.S., Zhao, W., Wang, J., Huang, A., Wen, S., Liao, B., and Appel, S.H. (2011a). Endogenous regulatory $\mathrm{T}$ lymphocytes ameliorate amyotrophic lateral sclerosis in mice and correlate with disease progression in patients with amyotrophic lateral sclerosis. Brain 134, 1293-1314.

Beers, D.R., Zhao, W., Liao, B., Kano, O., Wang, J., Huang, A., Appel, S.H., and Henkel, J.S. (2011b). Neuroinflammation modulates distinct regional and temporal clinical responses in ALS mice. Brain Behav Immun 25, 1025-1035.

Bendotti, C., Tortarolo, M., Suchak, S.K., Calvaresi, N., Carvelli, L., Bastone, A., Rizzi, M., Rattray, M., and Mennini, T. (2001). Transgenic SOD1 G93A mice develop reduced 
GLT-1 in spinal cord without alterations in cerebrospinal fluid glutamate levels. J Neurochem 79, 737-746.

Bensimon, G., Lacomblez, L., and Meininger, V. (1994). A controlled trial of riluzole in amyotrophic lateral sclerosis. ALS/Riluzole Study Group. N Engl J Med 330, 585591.

Boillee, S., Vande Velde, C., and Cleveland, D.W. (2006a). ALS: a disease of motor neurons and their nonneuronal neighbors. Neuron 52, 39-59.

Boillee, S., Yamanaka, K., Lobsiger, C.S., Copeland, N.G., Jenkins, N.A., Kassiotis, G., Kollias, G., and Cleveland, D.W. (2006b). Onset and progression in inherited ALS determined by motor neurons and microglia. Science 312, 1389-1392.

Boucherie, C., Schafer, S., Lavand'homme, P., Maloteaux, J.M., and Hermans, E. (2009). Chimerization of astroglial population in the lumbar spinal cord after mesenchymal stem cell transplantation prolongs survival in a rat model of amyotrophic lateral sclerosis. J Neurosci Res 87, 2034-2046.

Bristol, L.A., and Rothstein, J.D. (1996). Glutamate transporter gene expression in amyotrophic lateral sclerosis motor cortex. Ann Neurol 39, 676-679.

Bruijn, L.I., Miller, T.M., and Cleveland, D.W. (2004). Unraveling the mechanisms involved in motor neuron degeneration in ALS. Annu Rev Neurosci 27, 723-749.

Casula, M., Iyer, A.M., Spliet, W.G., Anink, J.J., Steentjes, K., Sta, M., Troost, D., and Aronica, E. (2011). Toll-like receptor signaling in amyotrophic lateral sclerosis spinal cord tissue. Neuroscience 179, 233-243.

Chiu, I.M., Chen, A., Zheng, Y., Kosaras, B., Tsiftsoglou, S.A., Vartanian, T.K., Brown, R.H., Jr., and Carroll, M.C. (2008). T lymphocytes potentiate endogenous neuroprotective inflammation in a mouse model of ALS. Proc Natl Acad Sci U S A 105, 17913-17918.

Cid, C., Alvarez-Cermeno, J.C., Regidor, I., Salinas, M., and Alcazar, A. (2003). Low concentrations of glutamate induce apoptosis in cultured neurons: implications for amyotrophic lateral sclerosis. J Neurol Sci 206, 91-95.

Corti, S., Nizzardo, M., Nardini, M., Donadoni, C., Salani, S., Simone, C., Falcone, M., Riboldi, G., Govoni, A., Bresolin, N., et al. (2010). Systemic transplantation of c-kit+ cells exerts a therapeutic effect in a model of amyotrophic lateral sclerosis. Hum Mol Genet 19, 3782-3796.

Crosio, C., Valle, C., Casciati, A., Iaccarino, C., and Carri, M.T. (2011). Astroglial inhibition of NF-kappaB does not ameliorate disease onset and progression in a mouse model for amyotrophic lateral sclerosis (ALS). PLoS One 6(3): e17187. doi:10.1371/ journal.pone.0017187.

Del Bo, R., Ghezzi, S., Corti, S., Pandolfo, M., Ranieri, M., Santoro, D., Ghione, I., Prelle, A., Orsetti, V., Mancuso, M., et al. (2009). TARDBP (TDP-43) sequence analysis in patients with familial and sporadic ALS: identification of two novel mutations. Eur J Neurol 16, 727-732.

Drachman, D.B., Frank, K., Dykes-Hoberg, M., Teismann, P., Almer, G., Przedborski, S., and Rothstein, J.D. (2002). Cyclooxygenase 2 inhibition protects motor neurons and prolongs survival in a transgenic mouse model of ALS. Ann Neurol 52, 771-778.

Fischer, L.R., and Glass, J.D. (2007). Axonal degeneration in motor neuron disease. Neurodegener Dis 4, 431-442.

Fiszman, M.L., Ricart, K.C., Latini, A., Rodriguez, G., and Sica, R.E. (2010). In vitro neurotoxic properties and excitatory aminoacids concentration in the cerebrospinal 
fluid of amyotrophic lateral sclerosis patients. Relationship with the degree of certainty of disease diagnoses. Acta Neurol Scand 121, 120-126.

Ganel, R., Ho, T., Maragakis, N.J., Jackson, M., Steiner, J.P., and Rothstein, J.D. (2006). Selective up-regulation of the glial Na+-dependent glutamate transporter GLT1 by a neuroimmunophilin ligand results in neuroprotection. Neurobiol Dis 21, 556-567.

Genestine, M., Caricati, E., Fico, A., Richelme, S., Hassani, H., Sunyach, C., Lamballe, F., Panzica, G.C., Pettmann, B., Helmbacher, F., et al. (2011). Enhanced neuronal Met signalling levels in ALS mice delay disease onset. Cell Death Dis 2, e130; doi:10.1038/cddis.2011.11.

Gowing, G., Dequen, F., Soucy, G., and Julien, J.P. (2006). Absence of tumor necrosis factoralpha does not affect motor neuron disease caused by superoxide dismutase 1 mutations. J Neurosci 26, 11397-11402.

Gowing, G., Lalancette-Hebert, M., Audet, J.N., Dequen, F., and Julien, J.P. (2009). Macrophage colony stimulating factor (M-CSF) exacerbates ALS disease in a mouse model through altered responses of microglia expressing mutant superoxide dismutase. Exp Neurol 220, 267-275.

Gowing, G., Philips, T., Van Wijmeersch, B., Audet, J.N., Dewil, M., Van Den Bosch, L., Billiau, A.D., Robberecht, W., and Julien, J.P. (2008). Ablation of proliferating microglia does not affect motor neuron degeneration in amyotrophic lateral sclerosis caused by mutant superoxide dismutase. J Neurosci 28, 10234-10244.

Grosskreutz, J., Van Den Bosch, L., and Keller, B.U. (2010). Calcium dysregulation in amyotrophic lateral sclerosis. Cell Calcium 47, 165-174.

Gu, R., Hou, X., Pang, R., Li, L., Chen, F., Geng, J., Xu, Y., and Zhang, C. (2010). Human adipose-derived stem cells enhance the glutamate uptake function of GLT1 in SOD1(G93A)-bearing astrocytes. Biochem Biophys Res Commun 393, 481-486.

Guo, H., Lai, L., Butchbach, M.E., Stockinger, M.P., Shan, X., Bishop, G.A., and Lin, C.L. (2003). Increased expression of the glial glutamate transporter EAAT2 modulates excitotoxicity and delays the onset but not the outcome of ALS in mice. Hum Mol Genet 12, 2519-2532.

Guo, Y., Duan, W., Li, Z., Huang, J., Yin, Y., Zhang, K., Wang, Q., Zhang, Z., and Li, C. (2010). Decreased GLT-1 and increased SOD1 and HO-1 expression in astrocytes contribute to lumbar spinal cord vulnerability of SOD1-G93A transgenic mice. FEBS Lett 584, 1615-1622.

Gurney, M.E., Pu, H., Chiu, A.Y., Dal Canto, M.C., Polchow, C.Y., Alexander, D.D., Caliendo, J., Hentati, A., Kwon, Y.W., Deng, H.X., et al. (1994). Motor neuron degeneration in mice that express a human $\mathrm{Cu}, \mathrm{Zn}$ superoxide dismutase mutation. Science 264, 1772-1775.

Haidet-Phillips, A.M., Hester, M.E., Miranda, C.J., Meyer, K., Braun, L., Frakes, A., Song, S., Likhite, S., Murtha, M.J., Foust, K.D., et al. (2011). Astrocytes from familial and sporadic ALS patients are toxic to motor neurons. Nat Biotechnol doi: 10.1038/ nbt.1957

Hensley, K., Abdel-Moaty, H., Hunter, J., Mhatre, M., Mou, S., Nguyen, K., Potapova, T., Pye, Q.N., Qi, M., Rice, H., et al. (2006). Primary glia expressing the G93A-SOD1 mutation present a neuroinflammatory phenotype and provide a cellular system for studies of glial inflammation. J Neuroinflammation 3, 2. 
Howland, D.S., Liu, J., She, Y., Goad, B., Maragakis, N.J., Kim, B., Erickson, J., Kulik, J., DeVito, L., Psaltis, G., et al. (2002). Focal loss of the glutamate transporter EAAT2 in a transgenic rat model of SOD1 mutant-mediated amyotrophic lateral sclerosis (ALS). Proc Natl Acad Sci U S A 99, 1604-1609.

Jaarsma, D., Teuling, E., Haasdijk, E.D., De Zeeuw, C.I., and Hoogenraad, C.C. (2008). Neuron-specific expression of mutant superoxide dismutase is sufficient to induce amyotrophic lateral sclerosis in transgenic mice. J Neurosci 28, 2075-2088.

Johnson, J.O., Mandrioli, J., Benatar, M., Abramzon, Y., Van Deerlin, V.M., Trojanowski, J.Q., Gibbs, J.R., Brunetti, M., Gronka, S., Wuu, J., et al. Exome sequencing reveals VCP mutations as a cause of familial ALS. Neuron 68, 857-864.

Keller, A.F., Gravel, M., and Kriz, J. (2009). Live imaging of amyotrophic lateral sclerosis pathogenesis: disease onset is characterized by marked induction of GFAP in Schwann cells. Glia 57, 1130-1142.

Keller, A.F., Gravel, M., and Kriz, J. (2011). Treatment with minocycline after disease onset alters astrocyte reactivity and increases microgliosis in SOD1 mutant mice. Exp Neurol 228, 69-79.

Kiaei, M., Kipiani, K., Petri, S., Chen, J., Calingasan, N.Y., and Beal, M.F. (2005). Celastrol blocks neuronal cell death and extends life in transgenic mouse model of amyotrophic lateral sclerosis. Neurodegener Dis 2, 246-254.

Kiaei, M., Petri, S., Kipiani, K., Gardian, G., Choi, D.K., Chen, J., Calingasan, N.Y., Schafer, P., Muller, G.W., Stewart, C., et al. (2006). Thalidomide and lenalidomide extend survival in a transgenic mouse model of amyotrophic lateral sclerosis. J Neurosci 26, 2467-2473.

Kriz, J., Nguyen, M.D., and Julien, J.P. (2002). Minocycline slows disease progression in a mouse model of amyotrophic lateral sclerosis. Neurobiol Dis 10, 268-278.

Kotchoubey, B., Lang, S., Winter, S., and Birbaumer, N. (2003). Cognitive processing in completely paralyzed patients with amyotrophic lateral sclerosis. Eur J Neurol 10, 551-558.

Kwiatkowski, T.J., Jr., Bosco, D.A., Leclerc, A.L., Tamrazian, E., Vanderburg, C.R., Russ, C., Davis, A., Gilchrist, J., Kasarskis, E.J., Munsat, T., et al. (2009). Mutations in the FUS/TLS gene on chromosome 16 cause familial amyotrophic lateral sclerosis. Science 323, 1205-1208.

Laake, J.H., Slyngstad, T.A., Haug, F.M., and Ottersen, O.P. (1995). Glutamine from glial cells is essential for the maintenance of the nerve terminal pool of glutamate: immunogold evidence from hippocampal slice cultures. J Neurochem 65, 871-881.

Lacomblez, L., Bensimon, G., Leigh, P.N., Guillet, P., and Meininger, V. (1996). Dose-ranging study of riluzole in amyotrophic lateral sclerosis. Amyotrophic Lateral Sclerosis/Riluzole Study Group II. Lancet 347, 1425-1431.

Lee, S.G., Su, Z.Z., Emdad, L., Gupta, P., Sarkar, D., Borjabad, A., Volsky, D.J., and Fisher, P.B. (2008). Mechanism of ceftriaxone induction of excitatory amino acid transporter-2 expression and glutamate uptake in primary human astrocytes. J Biol Chem 283, 13116-13123.

Lepore, A.C., Dejea, C., Carmen, J., Rauck, B., Kerr, D.A., Sofroniew, M.V., and Maragakis, N.J. (2008a). Selective ablation of proliferating astrocytes does not affect disease outcome in either acute or chronic models of motor neuron degeneration. Exp Neurol 211, 423-432. 
Lepore, A.C., Rauck, B., Dejea, C., Pardo, A.C., Rao, M.S., Rothstein, J.D., and Maragakis, N.J. (2008b). Focal transplantation-based astrocyte replacement is neuroprotective in a model of motor neuron disease. Nat Neurosci 11, 1294-1301.

Liang, X., Wang, Q., Shi, J., Lokteva, L., Breyer, R.M., Montine, T.J., and Andreasson, K. (2008). The prostaglandin E2 EP2 receptor accelerates disease progression and inflammation in a model of amyotrophic lateral sclerosis. Ann Neurol 64, 304-314.

Lobsiger, C.S., Boillee, S., McAlonis-Downes, M., Khan, A.M., Feltri, M.L., Yamanaka, K., and Cleveland, D.W. (2009). Schwann cells expressing dismutase active mutant SOD1 unexpectedly slow disease progression in ALS mice. Proc Natl Acad Sci U S A $106,4465-4470$.

Logroscino, G., Traynor, B.J., Hardiman, O., Chio, A., Mitchell, D., Swingler, R.J., Millul, A., Benn, E., and Beghi, E. (2010). Incidence of amyotrophic lateral sclerosis in Europe. J Neurol Neurosurg Psychiatry 81(4):385-90

Maessen, M., Veldink, J.H., van den Berg, L.H., Schouten, H.J., van der Wal, G., and Onwuteaka-Philipsen, B.D. (2010). Requests for euthanasia: origin of suffering in ALS, heart failure, and cancer patients. J Neurol 257, 1192-1198.

Marchetto, M.C., Muotri, A.R., Mu, Y., Smith, A.M., Cezar, G.G., and Gage, F.H. (2008). Non-cell-autonomous effect of human SOD1 G37R astrocytes on motor neurons derived from human embryonic stem cells. Cell Stem Cell 3, 649-657.

Maruyama, H., Morino, H., Ito, H., Izumi, Y., Kato, H., Watanabe, Y., Kinoshita, Y., Kamada, M., Nodera, H., Suzuki, H., et al. Mutations of optineurin in amyotrophic lateral sclerosis. Nature 465, 223-226.

Mayer, M.L. (2005). Glutamate receptor ion channels. Curr Opin Neurobiol 15, 282-288.

Miller, R.G., Mitchell, J.D., Lyon, M., and Moore, D.H. (2007). Riluzole for amyotrophic lateral sclerosis (ALS)/motor neuron disease (MND). Cochrane Database Syst Rev, CD001447.

Naor, S., Keren, Z., Bronshtein, T., Goren, E., Machluf, M., and Melamed, D. (2009). Development of ALS-like disease in SOD-1 mice deficient of B lymphocytes. J Neurol 256, 1228-1235.

Neymotin, A., Petri, S., Calingasan, N.Y., Wille, E., Schafer, P., Stewart, C., Hensley, K., Beal, M.F., and Kiaei, M. (2009). Lenalidomide (Revlimid) administration at symptom onset is neuroprotective in a mouse model of amyotrophic lateral sclerosis. Exp Neurol 220, 191-197.

Nguyen, M.D., D'Aigle, T., Gowing, G., Julien, J.P., and Rivest, S. (2004). Exacerbation of motor neuron disease by chronic stimulation of innate immunity in a mouse model of amyotrophic lateral sclerosis. J Neurosci 24, 1340-1349.

Papadimitriou, D., Le Verche, V., Jacquier, A., Ikiz, B., Przedborski, S., and Re, D.B. (2010). Inflammation in ALS and SMA: sorting out the good from the evil. Neurobiol Dis 37, 493-502.

Pardo, A.C., Wong, V., Benson, L.M., Dykes, M., Tanaka, K., Rothstein, J.D., and Maragakis, N.J. (2006). Loss of the astrocyte glutamate transporter GLT1 modifies disease in SOD1(G93A) mice. Exp Neurol 201, 120-130.

Philips, T., and Robberecht, W. (2011). Neuroinflammation in amyotrophic lateral sclerosis: role of glial activation in motor neuron disease. Lancet Neurol 10, 253-263.

Poloni, M., Facchetti, D., Mai, R., Micheli, A., Agnoletti, L., Francolini, G., Mora, G., Camana, C., Mazzini, L., and Bachetti, T. (2000). Circulating levels of tumour necrosis factor- 
alpha and its soluble receptors are increased in the blood of patients with amyotrophic lateral sclerosis. Neurosci Lett 287, 211-214.

Ransohoff, R.M., and Cardona, A.E. (2010). The myeloid cells of the central nervous system parenchyma. Nature 468, 253-262.

Raoul, C., Buhler, E., Sadeghi, C., Jacquier, A., Aebischer, P., Pettmann, B., Henderson, C.E., and Haase, G. (2006). Chronic activation in presymptomatic amyotrophic lateral sclerosis (ALS) mice of a feedback loop involving Fas, Daxx, and FasL. Proc Natl Acad Sci U S A 103, 6007-6012.

Raoul, C., Estevez, A.G., Nishimune, H., Cleveland, D.W., deLapeyriere, O., Henderson, C.E., Haase, G., and Pettmann, B. (2002). Motoneuron death triggered by a specific pathway downstream of Fas. potentiation by ALS-linked SOD1 mutations. Neuron 35, 1067-1083.

Reaume, A.G., Elliott, J.L., Hoffman, E.K., Kowall, N.W., Ferrante, R.J., Siwek, D.F., Wilcox, H.M., Flood, D.G., Beal, M.F., Brown, R.H., Jr., et al. (1996). Motor neurons in $\mathrm{Cu} / \mathrm{Zn}$ superoxide dismutase-deficient mice develop normally but exhibit enhanced cell death after axonal injury. Nat Genet 13, 43-47.

Rothstein, J.D., Patel, S., Regan, M.R., Haenggeli, C., Huang, Y.H., Bergles, D.E., Jin, L., Dykes Hoberg, M., Vidensky, S., Chung, D.S., et al. (2005). Beta-lactam antibiotics offer neuroprotection by increasing glutamate transporter expression. Nature 433, 73-77.

Rutherford, N.J., Zhang, Y.J., Baker, M., Gass, J.M., Finch, N.A., Xu, Y.F., Stewart, H., Kelley, B.J., Kuntz, K., Crook, R.J., et al. (2008). Novel mutations in TARDBP (TDP-43) in patients with familial amyotrophic lateral sclerosis. PLoS Genet 4, e1000193.

Sala, G., Beretta, S., Ceresa, C., Mattavelli, L., Zoia, C., Tremolizzo, L., Ferri, A., Carri, M.T., and Ferrarese, C. (2005). Impairment of glutamate transport and increased vulnerability to oxidative stress in neuroblastoma SH-SY5Y cells expressing a $\mathrm{Cu}, \mathrm{Zn}$ superoxide dismutase typical of familial amyotrophic lateral sclerosis. Neurochem Int 46, 227-234.

Sasaki, S., Warita, H., Abe, K., Komori, T., and Iwata, M. (2001). EAAT1 and EAAT2 immunoreactivity in transgenic mice with a G93A mutant SOD1 gene. Neuroreport $12,1359-1362$.

Schiffer, D., Cordera, S., Cavalla, P., and Migheli, A. (1996). Reactive astrogliosis of the spinal cord in amyotrophic lateral sclerosis. J Neurol Sci 139 Suppl, 27-33.

Seeburg, P.H., Single, F., Kuner, T., Higuchi, M., and Sprengel, R. (2001). Genetic manipulation of key determinants of ion flow in glutamate receptor channels in the mouse. Brain Res 907, 233-243.

Shefner, J.M., Reaume, A.G., Flood, D.G., Scott, R.W., Kowall, N.W., Ferrante, R.J., Siwek, D.F., Upton-Rice, M., and Brown, R.H., Jr. (1999). Mice lacking cytosolic copper/zinc superoxide dismutase display a distinctive motor axonopathy. Neurology 53, 1239-1246.

Shi, S.H., Hayashi, Y., Petralia, R.S., Zaman, S.H., Wenthold, R.J., Svoboda, K., and Malinow, R. (1999). Rapid spine delivery and redistribution of AMPA receptors after synaptic NMDA receptor activation. Science 284, 1811-1816.

Siniscalchi, A., Zona, C., Sancesario, G., D'Angelo, E., Zeng, Y.C., Mercuri, N.B., and Bernardi, G. (1999). Neuroprotective effects of riluzole: an electrophysiological and histological analysis in an in vitro model of ischemia. Synapse 32, 147-152. 
Spreux-Varoquaux, O., Bensimon, G., Lacomblez, L., Salachas, F., Pradat, P.F., Le Forestier, N., Marouan, A., Dib, M., and Meininger, V. (2002). Glutamate levels in cerebrospinal fluid in amyotrophic lateral sclerosis: a reappraisal using a new HPLC method with coulometric detection in a large cohort of patients. J Neurol Sci 193, 73-78.

Sta, M., Sylva-Steenland, R.M., Casula, M., de Jong, J.M., Troost, D., Aronica, E., and Baas, F. (2011). Innate and adaptive immunity in amyotrophic lateral sclerosis: evidence of complement activation. Neurobiol Dis 42, 211-220.

Staats, K.A., and Van Den Bosch, L. (2009). Astrocytes in amyotrophic lateral sclerosis: direct effects on motor neuron survival. J Biol Phys 35(4): p. 337-46.

Tanaka, K., Watase, K., Manabe, T., Yamada, K., Watanabe, M., Takahashi, K., Iwama, H., Nishikawa, T., Ichihara, N., Kikuchi, T., et al. (1997). Epilepsy and exacerbation of brain injury in mice lacking the glutamate transporter GLT-1. Science 276, 16991702.

Tateishi, T., Yamasaki, R., Tanaka, M., Matsushita, T., Kikuchi, H., Isobe, N., Ohyagi, Y., and Kira, J. (2010). CSF chemokine alterations related to the clinical course of amyotrophic lateral sclerosis. J Neuroimmunol 222, 76-81.

Tateno, M., Sugimoto, H., Tanaka, S., Itohara, H., Hama, A., Miyawaki, R.M., Shin, M.M., Masumada, T., Aosaki, H., Misawa, R., et al. (2002). GluR2 overexpression in motor neurons renders AMPA receptors impermeable to calcium and delays disease onset in an ALS transgenic mouse model. Soc for Neurosci Abstr 789.21

Tortarolo, M., Crossthwaite, A.J., Conforti, L., Spencer, J.P., Williams, R.J., Bendotti, C., and Rattray, M. (2004). Expression of SOD1 G93A or wild-type SOD1 in primary cultures of astrocytes down-regulates the glutamate transporter GLT-1: lack of involvement of oxidative stress. J Neurochem 88, 481-493.

Tortarolo, M., Grignaschi, G., Calvaresi, N., Zennaro, E., Spaltro, G., Colovic, M., Fracasso, C., Guiso, G., Elger, B., Schneider, H., et al. (2006). Glutamate AMPA receptors change in motor neurons of SOD1(G93A) transgenic mice and their inhibition by a noncompetitive antagonist ameliorates the progression of amytrophic lateral sclerosis-like disease. J Neurosci Res 83, 134-146.

Tovar, Y.R.L.B., Santa-Cruz, L.D., Zepeda, A., and Tapia, R. (2009). Chronic elevation of extracellular glutamate due to transport blockade is innocuous for spinal motoneurons in vivo. Neurochem Int 54, 186-191.

Van Damme, P., Bogaert, E., Dewil, M., Hersmus, N., Kiraly, D., Scheveneels, W., Bockx, I., Braeken, D., Verpoorten, N., Verhoeven, K., et al. (2007). Astrocytes regulate GluR2 expression in motor neurons and their vulnerability to excitotoxicity. Proc Natl Acad Sci U S A 104, 14825-14830.

Van Damme, P., Braeken, D., Callewaert, G., Robberecht, W., and Van Den Bosch, L. (2005). GluR2 deficiency accelerates motor neuron degeneration in a mouse model of amyotrophic lateral sclerosis. J Neuropathol Exp Neurol 64, 605-612.

Van Damme, P., Leyssen, M., Callewaert, G., Robberecht, W., and Van Den Bosch, L. (2003). The AMPA receptor antagonist NBQX prolongs survival in a transgenic mouse model of amyotrophic lateral sclerosis. Neurosci Lett 343, 81-84.

Van Deerlin, V.M., Leverenz, J.B., Bekris, L.M., Bird, T.D., Yuan, W., Elman, L.B., Clay, D., Wood, E.M., Chen-Plotkin, A.S., Martinez-Lage, M., et al. (2008). TARDBP 
mutations in amyotrophic lateral sclerosis with TDP-43 neuropathology: a genetic and histopathological analysis. Lancet Neurol 7, 409-416.

Van Den Bosch, L., Tilkin, P., Lemmens, G., and Robberecht, W. (2002). Minocycline delays disease onset and mortality in a transgenic model of ALS. Neuroreport 13, 1067-1070.

Vance, C., Rogelj, B., Hortobagyi, T., De Vos, K.J., Nishimura, A.L., Sreedharan, J., Hu, X., Smith, B., Ruddy, D., Wright, P., et al. (2009). Mutations in FUS, an RNA processing protein, cause familial amyotrophic lateral sclerosis type 6. Science 323, 1208-1211.

Wang, L., Gutmann, D.H., and Roos, R.P. (2011a). Astrocyte loss of mutant SOD1 delays ALS disease onset and progression in G85R transgenic mice. Hum Mol Genet 20, 286-293.

Wang, R., Yang, B., and Zhang, D. (2011b). Activation of interferon signaling pathways in spinal cord astrocytes from an ALS mouse model. Glia 59, 946-958.

Warita, H., Manabe, Y., Murakami, T., Shiote, M., Shiro, Y., Hayashi, T., Nagano, I., Shoji, M., and Abe, K. (2002). Tardive decrease of astrocytic glutamate transporter protein in transgenic mice with ALS-linked mutant SOD1. Neurol Res 24, 577-581.

Wilson, J.M., Khabazian, I., Pow, D.V., Craig, U.K., and Shaw, C.A. (2003). Decrease in glial glutamate transporter variants and excitatory amino acid receptor down-regulation in a murine model of ALS-PDC. Neuromolecular Med 3, 105-118.

Wilson, J.M., Khabazian, I., Wong, M.C., Seyedalikhani, A., Bains, J.S., Pasqualotto, B.A., Williams, D.E., Andersen, R.J., Simpson, R.J., Smith, R., et al. (2002). Behavioral and neurological correlates of ALS-parkinsonism dementia complex in adult mice fed washed cycad flour. Neuromolecular Med 1, 207-221.

Yamanaka, K., Chun, S.J., Boillee, S., Fujimori-Tonou, N., Yamashita, H., Gutmann, D.H., Takahashi, R., Misawa, H., and Cleveland, D.W. (2008). Astrocytes as determinants of disease progression in inherited amyotrophic lateral sclerosis. Nat Neurosci 11, 251-253.

Yang, E.J., Jiang, J.H., Lee, S.M., Yang, S.C., Hwang, H.S., Lee, M.S., and Choi, S.M. (2010). Bee venom attenuates neuroinflammatory events and extends survival in amyotrophic lateral sclerosis models. J Neuroinflammation 7, 69.

Yang, W.W., Sidman, R.L., Taksir, T.V., Treleaven, C.M., Fidler, J.A., Cheng, S.H., Dodge, J.C., and Shihabuddin, L.S. (2011). Relationship between neuropathology and disease progression in the SOD1(G93A) ALS mouse. Exp Neurol 227, 287-295.

Yang, Y., Gozen, O., Watkins, A., Lorenzini, I., Lepore, A., Gao, Y., Vidensky, S., Brennan, J., Poulsen, D., Won Park, J., et al. (2009). Presynaptic regulation of astroglial excitatory neurotransmitter transporter GLT1. Neuron 61, 880-894.

Yoshii, Y., Otomo, A., Pan, L., Ohtsuka, M., and Hadano, S. (2011). Loss of glial fibrillary acidic protein marginally accelerates disease progression in a SOD1(H46R) transgenic mouse model of ALS. Neurosci Res 70, 321-329.

Zhang, X., Chen, S., Li, L., Wang, Q., and Le, W. (2008). Folic acid protects motor neurons against the increased homocysteine, inflammation and apoptosis in SOD1 G93A transgenic mice. Neuropharmacology 54, 1112-1119.

Zhao, P., Ignacio, S., Beattie, E.C., and Abood, M.E. (2008). Altered presymptomatic AMPA and cannabinoid receptor trafficking in motor neurons of ALS model mice: implications for excitotoxicity. Eur J Neurosci 27, 572-579.

Zhu, S., Stavrovskaya, I.G., Drozda, M., Kim, B.Y., Ona, V., Li, M., Sarang, S., Liu, A.S., Hartley, D.M., Wu du, C., et al. (2002). Minocycline inhibits cytochrome c release and delays progression of amyotrophic lateral sclerosis in mice. Nature 417, 74-78. 
AMYOTROPHIC

LATERAL SCLEROSIS

Eaced by Marton H. maver

\section{Amyotrophic Lateral Sclerosis}

Edited by Prof. Martin Maurer
ISBN 978-953-307-806-9

Hard cover, 718 pages

Publisher InTech

Published online 20, January, 2012

Published in print edition January, 2012

Though considerable amount of research, both pre-clinical and clinical, has been conducted during recent years, Amyotrophic Lateral Sclerosis (ALS) remains one of the mysterious diseases of the 21st century. Great efforts have been made to develop pathophysiological models and to clarify the underlying pathology, and with novel instruments in genetics and transgenic techniques, the aim for finding a durable cure comes into scope. On the other hand, most pharmacological trials failed to show a benefit for ALS patients. In this book, the reader will find a compilation of state-of-the-art reviews about the etiology, epidemiology, and pathophysiology of ALS, the molecular basis of disease progression and clinical manifestations, the genetics familial ALS, as well as novel diagnostic criteria in the field of electrophysiology. An overview over all relevant pharmacological trials in ALS patients is also included, while the book concludes with a discussion on current advances and future trends in ALS research.

\section{How to reference}

In order to correctly reference this scholarly work, feel free to copy and paste the following:

Kim Staats and Ludo Van Den Bosch (2012). The Astrocytic Contribution in ALS: Inflammation and Excitotoxicity, Amyotrophic Lateral Sclerosis, Prof. Martin Maurer (Ed.), ISBN: 978-953-307-806-9, InTech, Available from: http://www.intechopen.com/books/amyotrophic-lateral-sclerosis/the-astrocytic-contribution-inals-inflammation-and-excitotoxicity

\section{INTECH}

open science | open minds

\section{InTech Europe}

University Campus STeP Ri

Slavka Krautzeka 83/A

51000 Rijeka, Croatia

Phone: +385 (51) 770447

Fax: +385 (51) 686166

www.intechopen.com

\section{InTech China}

Unit 405, Office Block, Hotel Equatorial Shanghai

No.65, Yan An Road (West), Shanghai, 200040, China

中国上海市延安西路65号上海国际贵都大饭店办公楼 405 单元

Phone: +86-21-62489820

Fax: $+86-21-62489821$ 
(C) 2012 The Author(s). Licensee IntechOpen. This is an open access article distributed under the terms of the Creative Commons Attribution 3.0 License, which permits unrestricted use, distribution, and reproduction in any medium, provided the original work is properly cited. 